\title{
Pharmacovigilance in Sudan: Knowledge, Attitudes and Behaviour among Community Pharmacists
}

\author{
Babiker Osman $\mathrm{AMH}^{1}$ and Mohamed Awad $\mathrm{M}^{2 *}$ \\ ${ }^{1}$ Faculty of pharmacy, Omdurman Islamic university, Sudan \\ ${ }^{2}$ Department of pharmacy practice, faculty of pharmacy, international university of Africa, \\ Sudan
}

*Corresponding author: Mohamed Awad Mousnad, Department of pharmacy practice, faculty of pharmacy, International University of Africa, Sudan, Tel: +249-912325864; E-mail:

\section{Research Article \\ Volume 4 Issue 1}

Received Date: January 28, 2021

Published Date: February 22, 2021

DOI: $10.23880 /$ jqhe- 16000207

m_abdalaziz@yahoo.com

\section{Abstract}

Background: Adverse drug reaction monitoring and reporting require a multidisciplinary approach and pharmacists have a major role to play in this matter. Under-reporting of the ADRs by the prescribers is a common problem in devolving countries. Aim: To assess the knowledge, attitude and behaviour of community pharmacists toward pharmacovigilance in Khartoum city. Method: Descriptive cross-sectional study among 258 community pharmacists during the period from October to November 2017 using a pre-designed questionnaire. The study was evaluated participants regarding knowledge on drug safety in routine practice, the knowledge and attitude of community pharmacists toward ADR reporting and their behaviour on ADR related aspects.

Result: Out of 325 participants, most of them were male (50.8\%) with age group From 18 years to 30 years (62\%) and B. Pharm (57.8\%) and practice experience more than 2 years to 5 years $(38.8 \%)$ and Training received in pharmacovigilance Yes (42.2\%). Assessing pharmacist's knowledge showed that $74 \%$ of community pharmacists know the ADR definition and $39.5 \%$ are not know the ADR are preventable to some extent, no association between knowledge and qualification, and there is an association with practice. Assessing pharmacists knowledge toward ADR reporting, 69\% of the participant are agree awareness of the national pharmacovigilance program in Sudan revealed no statistically significant association with training in pharmacovigilance, positive attitude of pharmacist toward ADR reporting, $67.8 \%$ of the pharmacists believed that the role of the pharmacist in ADR reporting was essential revealed there are statistically significant associations with training in pharmacovigilance, the behaviour of pharmacist toward ADR, 91.9\%of participant agrees to ask for the allergy history of the patient before dispensing the medication revealed no statistically significant association with training in pharmacovigilance. Conclusion: Even though most of the pharmacists had knowledge, attitude and behaviour on ADR reporting and related aspects, the number of them did not know drug safety-related aspects of specific drugs. Educational programs have to be generated awareness on how to report ADR and stimulate pharmacists' more active participation in the pharmacovigilance program. There is a true need to have training programs to improve the knowledge of pharmacists on ADR related aspects that are of benefit daily, which could greatly have an impact on patient safety.

Key Policy Messages: The result reflected pharmacists knowledge toward ADR reporting, most of the participant are agree awareness of the national pharmacovigilance program in Sudan revealed no statistically significant association with training in pharmacovigilance, positive attitude of pharmacist toward ADR reporting, most of the pharmacists believed that the role of the pharmacist in ADR reporting was essential revealed there are statistically significant associations with training in pharmacovigilance, the behaviour of pharmacist toward ADR, majority of the participant agrees to ask for the allergy history of the patient before dispensing the medication revealed no statistically significant association with training in pharmacovigilance.

Keywords: Pharmacovigilance; ADR; Marketed Drugs; Patients 


\section{Introduction and Background}

Pharmacovigilance is the science and activities relating to the detection, assessment, understanding, and prevention of adverse effects or any other drug-related problems and generally refers to the continual monitoring for unwanted effects and other safety-related aspects of marketed drugs [1].

The Royal College of Physicians in 1994: Pharmacovigilance is the process of identifying, and then responding to, safety issues about marketed drugs [2].

In their latest textbook, Mann and Andrews define pharmacovigilance as 'the Study of the safety of marketed drugs under the practical conditions of clinical Usage in large communities' [3]. But this includes more as only collecting reports of possible adverse drug reactions (ADRs) and looking for signals of new ADRs. Reasons why drug safety issues may not be identified until the post-marketing Period, The adverse reaction is rare and therefore undetectable until a large number of patients have been exposed to the drug, there is a long latency between starting the drug and development of the adverse reaction and The drug has not been studied in normal clinical practice: patients treated in clinical practice are likely to have different characteristics to a trial patient (e.g. demography, other diseases, other medication); in clinical practice, a drug is less likely to be used strictly following the recommendations by both doctors and patients, and with less monitoring [4].

In the past pharmacovigilance was repeatedly criticized because once its activities had yielded a signal of an ADR this all too often meant that the license of the drug concerned was suspended. Today it has become one of the pharmacovigilance's priorities to try and find more creative and constructive ways to deal with these signals [5].

Pharmacovigilance concerns itself with all the aspects in the circle of knowledge and practice. Besides tracing and weighing risk factors, it tries to advise doctors and pharmacists on how best to deal with these risks and provide them with tools that will enable them to apply their newly acquired knowledge to the treatment of the individual patient. This approach permits pharmacovigilance to contribute to the safe and rational use of drugs for the benefit and well-being of those patients that are dependent on pharmacotherapy. Pharmacovigilance concerns itself with all the aspects in the circle of knowledge and practice. Besides tracing and weighing risk factors, it tries to advise doctors and pharmacists on how best to deal with these risks and provide them with tools that will enable them to apply their newly acquired knowledge to the treatment of the individual patient. This approach permits pharmacovigilance to contribute to the safe and rational use of drugs for the benefit and well-being of those patients that are dependent on pharmacotherapy [6].

The signals of adverse drug reactions derived from the experiences with patients using the drugs as reported by doctors and pharmacists lie at the heart of pharmacovigilance. Meyboom, et al. [7] defined a signal as a set of data constituting a hypothesis that is relevant to the rational and safe use of a drug in humans.

Pharmacists play an important role in the field of medicinal drugs including in the scientific field dealing with the safety of drugs - pharmacovigilance. The participation of the pharmacist in national spontaneous reporting systems for ADRs helps in improving pharmacovigilance conception. The countries that received fewer reports from pharmacists gave lower scores to their contribution.

Concerning pharmacovigilance, both sound clinical judgement of the ADR and insight into the effects of the drug are required to allow a conclusion to be drawn as to the relationship between the adverse event and the drug involved.

Currently, the role of the pharmacist in the reporting of adverse drug reactions is not appreciated everywhere. In the Scandinavian countries, for instance, pharmacists are not authorized to report ADRs [8-9]. In the United Kingdom, they have only recently been allowed to report independently [10]. By contrast, in the Netherlands $40 \%$ of the reports on ADRs are submitted by of pharmacovigilance is substantial [11]. In 1989 Fincham comments: 'Exclusion of pharmacists simply does not make sense [12]. In their 1993 article on the differences between European countries Lindquist and Edwards remark: 'Pharmacists who pharmacists and their role in the maintenance advise patients directly are the most likely to detect adverse reactions [13].

The premarketing evaluation of drug safety in phase 1-3 clinical trial provides insufficient evidence of safety. There is a lack of studies that address the knowledge, attitudes and practice toward the pharmacovigilance system and ADRs reporting. It is important to conduct comprehensive studies to explore and evaluate the roles of healthcare professionals and their contributions in the pharmacovigilance activities.

\section{This Study Aims}

To assess the knowledge, attitude and behaviour of community pharmacists toward pharmacovigilance in Khartoum city in 2017. To evaluate the knowledge of pharmacists on some of selected basic aspects of drug safety and to determine the Knowledge, attitude of community 
pharmacists toward ADR reporting and their behaviour on ADR related aspects.

\section{Materials and Methods}

A descriptive cross-sectional study among community pharmacies using a structured and pilot-tested questionnaire the study was conducted in community pharmacies in Khartoum city. According to enumeration obtain from the ministry of health of Khartoum state, the total number of community pharmacies in Khartoum state is 1876 . The distribution of pharmacies in Khartoum state 741; pharmacies in Khartoum (39.4\%).

\section{Study Population}

Community pharmacist working in pharmacies of Khartoum city.

\section{Inclusion Criteria}

Community pharmacists working in determining pharmacies who agree to fill the questionnaire.

\section{Exclusion Criteria}

A pharmacist who refused to participate in the study or who did not fulfil inclusion criteria.

\section{Sample Size}

According to Solvin's formula.

$$
\mathrm{n}=\frac{\mathrm{N}}{1+\mathrm{N}(\mathrm{e})^{2}}
$$

Whereas:

$\mathrm{n}=$ no. of samples

$\mathrm{N}=$ total population

e = error margin / margin of error (0.05)

$=741 / 1+741(0.05) 2=260$

So number of pharmacists are 260 .

Two pharmacists refuse to participate and thus the total of the respondent is 258 .

\section{Data Collection Procedure}

A sample of 260 pharmacies was obtained from 741 pharmacies of Khartoum city by stratified random sampling. 258 pharmacies located in Khartoum city were included in the sample which represents $99 \%$ of 260 total samples. Each pharmacy in the city was given a number then systemic random sampling was performed to select the pharmacies within the city. The pharmacist was given a concise explanation of the purpose of the study and then asked if he wants to participate in the study then the data were collected using a predesigned questionnaire.

\section{Study Duration}

This study was performed in the period from October to November 2017.

\section{Data Analysis Plan}

Data were analysed using statistical package for social science (SPSS), based on 95\% confidence level as the p-value of $(<0.05)$ was considered significant. The results were expressed in form of tables and figures using Microsoft Excel.

\section{Ethical Consideration}

Verbal consent has been obtained from each participant.

\section{Result}

\section{Demographic Characteristics of the Study Sample}

Majority of community pharmacists at Khartoum city are male $(50.8 \%)$ with age group From 18 years to 30 years $(62 \%)$ and B. Pharm (57.8\%) and practice experience more than 2 years to 5 years $(38.8 \%)$ and Training received in pharmacovigilance Yes (42.2\%) as shown in Figures 1-5 respectively.

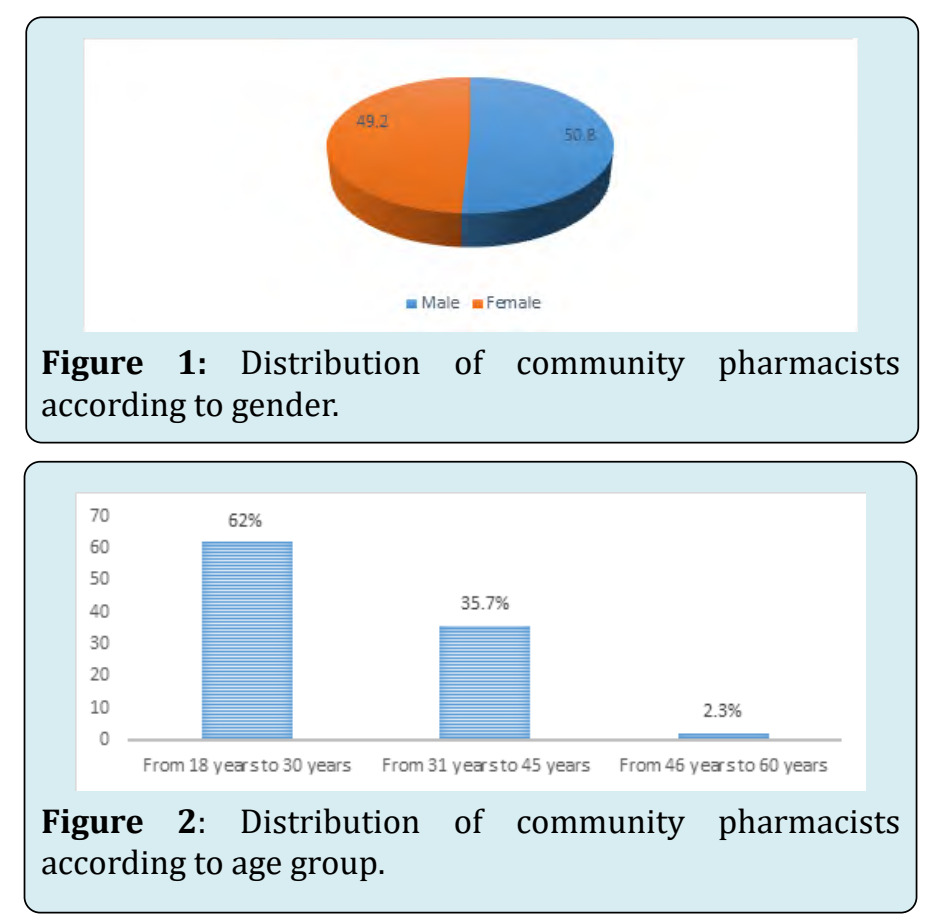



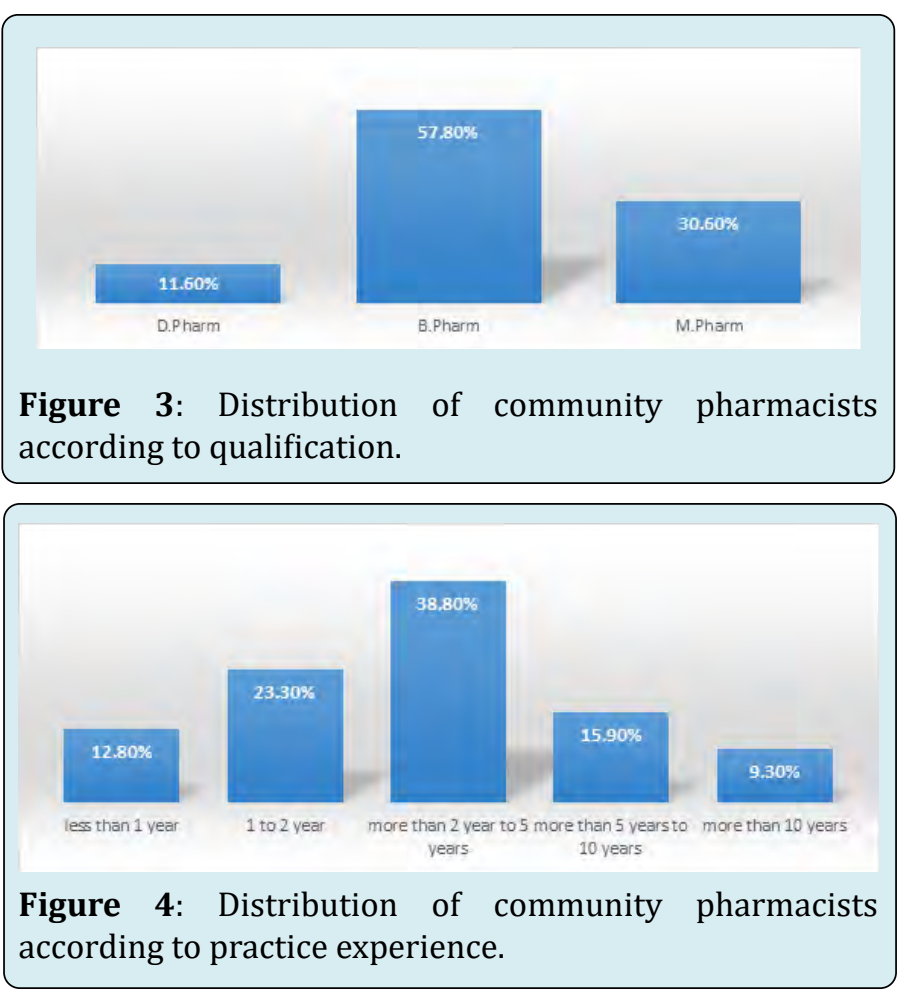

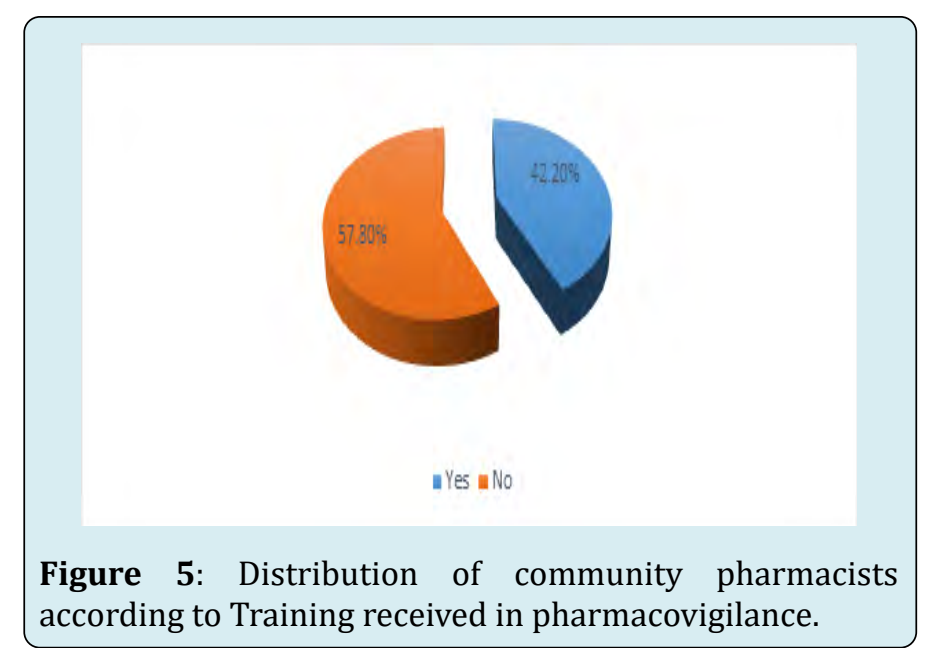

\section{Assessment of Knowledge of Community Pharmacists on Drug Safety in Routine Practice}

Only $74 \%$ of community pharmacists know the ADR definition and $39.5 \%$ are not know the ADR are preventable to some extend as illustrated in Table 1.

\begin{tabular}{|c|c|c|c|}
\hline & & Frequency & Per cent \\
\hline \multirow[t]{3}{*}{ Q1 } & Correct & 191 & $74 \%$ \\
\hline & wrong & 67 & $26 \%$ \\
\hline & Total & 258 & $100 \%$ \\
\hline \multirow[t]{3}{*}{ Q2 } & Correct & 156 & $60.50 \%$ \\
\hline & wrong & 102 & $39.50 \%$ \\
\hline & Total & 258 & $100 \%$ \\
\hline \multirow[t]{3}{*}{ Q3 } & Correct & 165 & $64 \%$ \\
\hline & wrong & 93 & $36 \%$ \\
\hline & Total & 258 & $100 \%$ \\
\hline \multirow[t]{3}{*}{ Q4 } & Correct & 82 & $31.80 \%$ \\
\hline & wrong & 176 & $68.20 \%$ \\
\hline & Total & 258 & $100 \%$ \\
\hline \multirow[t]{3}{*}{ Q5 } & Correct & 135 & $52.30 \%$ \\
\hline & wrong & 123 & $47.70 \%$ \\
\hline & Total & 258 & $100 \%$ \\
\hline \multirow[t]{3}{*}{ Q6 } & Correct & 98 & $38 \%$ \\
\hline & wrong & 160 & $62 \%$ \\
\hline & Total & 258 & $100 \%$ \\
\hline \multirow[t]{2}{*}{ Q7 } & Correct & 193 & $74.80 \%$ \\
\hline & wrong & 65 & $25.20 \%$ \\
\hline
\end{tabular}




\begin{tabular}{|c|c|c|c|}
\hline & Total & 258 & $100 \%$ \\
\hline Q8 & Correct & 13 & $5 \%$ \\
\hline & wrong & 245 & $95 \%$ \\
\hline & Total & 258 & $100 \%$ \\
\hline & Correct & 171 & $66.30 \%$ \\
\hline & wrong & 87 & $33.70 \%$ \\
\hline
\end{tabular}

Table 1: Frequency of assessment of knowledge among community pharmacists regarding drug safety in routine practice.

Majority of the community pharmacist (69\%) agrees, awareness of the National Pharmacovigilance Program in Sudan, (38.8\%) disagree Only ADRs to new drugs to be reported to the regulatory agency or drug company, (67.8\%) are agree Reporting of ADRs is a professional responsibility of the pharmacists, (55.4\%) disagree Reporting of ADRs adds up to unnecessary workload and (91.9\%) agree Ask for the allergy history of the patient before dispensing the medication as shown in Table 2.

\begin{tabular}{|c|c|c|c|}
\hline & & Frequency & Per cent \\
\hline \multirow{4}{*}{ Q1 } & Agree & 178 & $69 \%$ \\
\hline & Neutral & 61 & $23.60 \%$ \\
\hline & disagree & 19 & $7.40 \%$ \\
\hline & Total & 258 & 100 \\
\hline \multirow{4}{*}{ Q2 } & Agree & 120 & $46.50 \%$ \\
\hline & Neutral & 38 & $14.70 \%$ \\
\hline & disagree & 100 & $38.80 \%$ \\
\hline & Total & 258 & $100 \%$ \\
\hline \multirow{4}{*}{ Q3 } & Agree & 120 & $46.50 \%$ \\
\hline & Neutral & 38 & $14.70 \%$ \\
\hline & disagree & 100 & $38.80 \%$ \\
\hline & Total & 258 & $100 \%$ \\
\hline \multirow{4}{*}{ Q4 } & Agree & 231 & $89.50 \%$ \\
\hline & Neutral & 18 & $7 \%$ \\
\hline & disagree & 9 & $3.50 \%$ \\
\hline & Total & 258 & $100 \%$ \\
\hline \multirow{4}{*}{ Q5 } & Agree & 175 & $67.80 \%$ \\
\hline & Neutral & 63 & $24.40 \%$ \\
\hline & disagree & 20 & $7.80 \%$ \\
\hline & Total & 258 & $100 \%$ \\
\hline \multirow{4}{*}{ Q6 } & Agree & 81 & $31.40 \%$ \\
\hline & Neutral & 34 & $13.20 \%$ \\
\hline & disagree & 143 & $55.40 \%$ \\
\hline & Total & 258 & $100 \%$ \\
\hline \multirow{4}{*}{ Q7 } & Agree & 203 & $78.70 \%$ \\
\hline & Neutral & 41 & $15.90 \%$ \\
\hline & disagree & 14 & $5.40 \%$ \\
\hline & Total & 258 & $100 \%$ \\
\hline
\end{tabular}




\begin{tabular}{|c|c|c|c|}
\hline \multirow{4}{*}{ Q8 } & Agree & 237 & $91.90 \%$ \\
\cline { 2 - 4 } & Neutral & 21 & $8.10 \%$ \\
\cline { 2 - 4 } & disagree & 0 & $0 \%$ \\
\cline { 2 - 4 } & Total & 258 & $100 \%$ \\
\hline \multirow{4}{*}{ Q9 } & Agree & 227 & $88 \%$ \\
\cline { 2 - 4 } & Neutral & 23 & $3.10 \%$ \\
\cline { 2 - 4 } & disagree & 8 & $100 \%$ \\
\hline \multirow{4}{*}{ Q10 } & Total & 258 & $89.90 \%$ \\
\cline { 2 - 4 } & Agree & 232 & $7.80 \%$ \\
\cline { 2 - 4 } & Neutral & 20 & $2.30 \%$ \\
\cline { 2 - 4 } & disagree & 6 & $100 \%$ \\
\hline
\end{tabular}

Table 2: Frequency of knowledge attitude and behaviour among community pharmacists regarding ADR.

\begin{tabular}{|c|c|c|c|c|c|}
\hline & & & \multicolumn{3}{|c|}{ Answer } \\
\hline \multirow{14}{*}{ Q1 } & \multirow{6}{*}{ Qualification } & D.Pharm & 20 & 10 & 30 \\
\hline & & B.Pharm & 107 & 42 & 149 \\
\hline & & M.Pharm & 64 & 15 & 79 \\
\hline & & Total & 191 & 67 & 258 \\
\hline & & Value & 3.231 & & \\
\hline & & $\mathrm{p}$-value & 0.199 & & \\
\hline & \multirow{8}{*}{ Years of experience } & less than 1 year & 21 & 12 & 33 \\
\hline & & 1 to 2 year & 45 & 15 & 60 \\
\hline & & more than 2 years to 5 years & 66 & 34 & 100 \\
\hline & & more than 5 years to 10 years & 37 & 4 & 41 \\
\hline & & more than 10 years & 22 & 2 & 24 \\
\hline & & Total & 191 & 67 & 258 \\
\hline & & Value & 14.727 & & \\
\hline & & $\mathrm{p}$-value & 0.005 & & \\
\hline \multirow{14}{*}{ Q2 } & \multirow{6}{*}{ Qualification } & D.Pharm & 14 & 16 & 30 \\
\hline & & B.Pharm & 90 & 59 & 149 \\
\hline & & M.Pharm & 52 & 27 & 79 \\
\hline & & Total & 156 & 102 & 258 \\
\hline & & Value & 3.338 & & \\
\hline & & $\mathrm{p}$-value & 0.188 & & \\
\hline & \multirow{8}{*}{ Years of experience } & less than 1 year & 24 & 9 & 33 \\
\hline & & 1 to 2 year & 36 & 24 & 60 \\
\hline & & more than 2 year to 5 years & 47 & 53 & 100 \\
\hline & & more than 5 years to 10 years & 27 & 14 & 41 \\
\hline & & more than 10 years & 22 & 2 & 24 \\
\hline & & Total & 156 & 102 & 258 \\
\hline & & Value & 19.938 & & \\
\hline & & $\mathrm{p}$-value & 0.001 & & \\
\hline
\end{tabular}

Table 3: Association between knowledge frequency and demographic variables. 
Cross tabulation and chi-square test of knowledge frequency versus demographic variables revealed no significant association (p. value $>0.05$ ) as illustrated in Table 3.

\begin{tabular}{|c|c|c|c|c|c|}
\hline & & & Correct & Wrong & Total \\
\hline \multirow{5}{*}{ Q1 } & \multirow{5}{*}{ Training in pharmacovigilance } & Yes & 22 & 86 & 108 \\
\hline & & No & 38 & 111 & 149 \\
\hline & & Total & 60 & 197 & 257 \\
\hline & & Value & 0.922 & & \\
\hline & & P-value & 0.337 & & \\
\hline \multirow{5}{*}{ Q2 } & \multirow{5}{*}{ Training in pharmacovigilance } & Yes & 32 & 76 & 108 \\
\hline & & No & 68 & 81 & 149 \\
\hline & & Total & 100 & 157 & 257 \\
\hline & & Value & 6.75 & & \\
\hline & & P-value & 0.009 & & \\
\hline \multirow{5}{*}{ Q5 } & \multirow{5}{*}{ Training in pharmacovigilance } & Yes & 64 & 45 & 109 \\
\hline & & No & 111 & 38 & 149 \\
\hline & & Total & 175 & 83 & 258 \\
\hline & & Value & 7.184 & & \\
\hline & & P-value & 0.007 & & \\
\hline \multirow{5}{*}{ Q6 } & \multirow{5}{*}{ Training in pharmacovigilance } & Yes & 44 & 65 & 109 \\
\hline & & No & 100 & 49 & 149 \\
\hline & & Total & 144 & 114 & 258 \\
\hline & & Value & 18.261 & & \\
\hline & & P-value & 0 & & \\
\hline \multirow{5}{*}{ Q8 } & \multirow{5}{*}{ Training in pharmacovigilance } & Yes & 99 & 10 & 109 \\
\hline & & No & 138 & 11 & 149 \\
\hline & & Total & 237 & 21 & 258 \\
\hline & & Value & 0.27 & & \\
\hline & & P-value & 0.603 & & \\
\hline
\end{tabular}

Table 4: Association between knowledge attitude, behaviour frequency and demographic variables.

Cross tabulation and chi-square test of knowledge frequency versus demographic variables revealed no significant association (p. value $>0.05$ ) as illustrated in Table 4.

\section{Discussion}

Knowledge and attitude of pharmacists on drug safetyrelated aspects could greatly influence their behaviour and thereby contribute to patient safety [14]. No randomized studies have tested the knowledge, attitude and practice of community pharmacist towards ADR, current study attempt to assess such issue among community pharmacists in Khartoum city. The study target 260 pharmacists out of whom 258 involved with a response rate of $99 \%$.

Among 258 participate, male predominated with the percentage of $50.8 \%$ versus $49.2 \%$ female, this is similar to Jose et al stated that majority of the participants in the study were males [15]. Age group distribution represented that, a pharmacist with age from 18 to 30 years has higher distribution are $62 \%$, from 31 to 45 years are $35.7 \%$ and from 46 to 60 years are $2.3 \%$. This is same with Jose et al stated that majority of the participants in the study were age from 18 to 30 years [16].

Qualification distribution revealed that pharmacist with bachelors' degree represents the vast majority group with 
percentage $57.8 \%$ while remaining $30.6 \%$ with a master degree in pharmacy and $11.6 \% \mathrm{PhD}$ holder, this is same with $\mathrm{S}$ Mohamed, et al. [17] stated that, majority of community pharmacists in Sudan with B. Pharm.

On other hand the predominated group found to have more than 2 year to 5 years $38.8 \%$ while pharmacists with experience less than one year represent $12.8 \%$ and one to two years is $23.3 \%$ and more than five to ten years are $15.9 \%$ and with more than 10 years are $9.3 \%$, this may be due to the majority of pharmacists want to get the experience of two years in pharmacies then seek another chance of jobs like companies, factories or migrate aboard, this in line with Jose, et al. [18] stated that predominant practice experience in community pharmacies is from 0-5 years.

Distribution of community pharmacists according to Training received in pharmacovigilance was found to be $42.2 \%$ of pharmacist received while $57.8 \%$ of pharmacist not received. This is same with Jose et al stated that majority of the participants in the study were not received any sort of training in ADR [19].

Assessing pharmacist's knowledge showed that, 74\% of the participant was defined the ADR, 39.5\% are not know the ADR are preventable to some extent, $64 \%$ are Know the most common ADR with anti-tubercular drugs, $68.2 \%$ are not known amlodipine is not safe during pregnancy, $52.3 \%$ are known palpitation is the side effect of salbutamol inhaler, $62 \%$ are not known Gingival hyperplasia is more common with amlodipine, $74.8 \%$ are known metallic taste is more commonly caused by metronidazole, $95 \%$ are not known dry cough with enalapril is more likely occur in female, $66.3 \%$ are known NSAID induce ulcer in elderly, those who are taking steroids with NSAIDs and Alcoholics. We could not find published studies evaluating the knowledge of pharmacists specifically to certain drugs or reactions to make effective comparisons for these results. In my opinion, this may due to a shortage in the university curriculum regarding pharmacovigilance and lack of interest of pharmacists to read or to know what is new in world of pharmacotherapy after graduation.

Responses of pharmacist to the knowledge of community pharmacists toward ADR reporting are showed that $69 \%$ of the participant agrees on awareness of the national pharmacovigilance program in Sudan which is a good indicator of the effectiveness of the activities carried out by regulatory agencies in Sudan in raising awareness on ADR reporting. This was, same as the results obtained in the study conducted among community pharmacists in Oman, Jose et al almost all of them were aware of the National Pharmacovigilance program in Oman [20].
Responses of the attitude of pharmacists toward ADR related activities; it was encouraging to note that almost all of them were in agreement that reporting of ADR helps in adding up to existing knowledge on ADR to old and new drugs and the majority of the participants considered reporting of ADRs as a professional responsibility of the pharmacists. This was similar with the study conducted in Saudi Arabia Bawazir, et al. [21] where $97 \%$ of them considered reporting of ADRs to be an integral part of pharmaceutical care and in Turkey Toklu, et al. [19] where $89 \%$ of the pharmacists believed that the role of the pharmacist in ADR reporting was essential.

Responses of the behaviour of pharmacists toward ADR related activities, around $78.8 \%$ of the participants claimed that they report ADRs to the regulatory agency in Sudan or the Drug Company. This was similar to the study conducted in Oman Jose et al around $70 \%$ of the participants claimed that they report ADRs to the regulatory agency in Oman or the Drug Company. $91.9 \%$ of the participant agrees to ask for the allergy history of the patient before dispensing the medication and $89.9 \%$ agrees to inform patients of the methods to prevent ADRs of the dispensed medications. This same with Toklu, et al. [23] it was encouraging to note that community pharmacists reported asking for allergy history before dispensing medicines and informing patients of important side effects and methods to prevent ADRs.

$31.4 \%$ of the participant are agree reporting of ADRs adds up to unnecessary workload, several factors were identified by the community pharmacist which discourage them from reporting of ADRs; lack of awareness on how to report ADRs and concern that the report may be wrong as the commonest factors. These factors have to be addressed and effectively solved during the educational/ awareness programs conducted for the pharmacists. Similarly in the study conducted among community pharmacists in Saudi Arabia Bawazir, et al. [16] several barriers were identified that prevent pharmacists from reporting ADR including, unknown address, reporting form not available, do not know how to report.

Cross-tabulation between demographic data (qualification and practice experience) and knowledge of pharmacists on the basic aspects on drug safety in routine practice revealed no statistically significant association with qualification (P-value <0.05), while there is a statistically significant association with practice experience (P-value $>0.05$ ) in the definition of ADR and the ADR is preventable to some extent, this in line with Jose et al who found that there is a significant association between knowledge and demographics data. 
Cross-tabulation between the knowledge, attitude and behaviour on ADR reporting and demographic data (receiving training in pharmacovigilance), knowledge of community pharmacists toward ADR reporting is showed that $69 \%$ of the participant agrees awareness of the national pharmacovigilance program in Sudan revealed no statistically significant association (P-value $<0.05)$ this is mean that reporting of ADR does not affect by knowledge. This is same in the study conducted in Malaysia there is no significant difference in knowledge with ADR reporting (28). The attitude of pharmacists toward ADR reporting $67.8 \%$ of the pharmacists believed that the role of the pharmacist in ADR reporting was essential revealed there are statistically significant associations (P-value $>0.05$ ) suggesting that reporting of ADR increase with attitude. The behaviour of pharmacists toward ADR reporting, $91.9 \%$ of the participant agrees to ask for the allergy history of the patient before dispensing the medication revealed no statistically significant association (P-value $<0.05$ ) this is mean that reporting of ADR did not affect by behaviour.

\section{Conclusion}

The study concluded that the majority of community pharmacist's knowledge on drug safety-related aspects define ADR and know the ADR is preventable to some extent, no significant association between knowledge and qualification but Practice showed significant association with knowledge.

\section{References}

1. Piro Di, Joseph T (2008) Pharmacotherapy: A Pathophysiologic Approach. New York: McGraw-Hill Medical.

2. Rawlins MD (1995) Pharmacovigilance: paradise lost, regained or postponed. The William Withering Lecture 1994. J Royal Coll Phys London 29(1): 41-49.

3. Mann R, Andrews E (2002) Pharmacovigilance. Wiley Chichester.

4. Waller PC, Arlett P (2002) Responding to signals. In: Pharmacovigilance. Mann R, Andrews E, et al. (Eds.), Wiley Chicester.

5. Seligman PJ (2003) Dear Doctor Evaluating the impact of risk communication efforts. Pharmacoepidemiol Drug Saf 12(4): 291-294.

6. Edwards IR, Hugman B (1997) The challenge of effectively communicating risk-benefit information. Drug saf 17(4): 216-227.

7. Meyboom RHB, Egberts ACG, Edward IR, Hekster YA,
Koning FHP de, et al. (1997) Principles of Signal Detection in Pharmacovigilance. Drug Saf 16(6): 355-365.

8. Olsson S (1999) National Pharmacovigilance SystemsCountry Profiles and Overview (second edition). Uppsala Monitoring Centre, Uppsala.

9. Saarinen S (2002) Adverse drug reaction reportingcomparison between Finland and The Netherlands. Master's thesis. University of Kuopio. Kuopio.

10. Major E (2020) The yellow card scheme and the role of pharmacists as reporters. Pharm J 269: 25-26.

11. Grootheest AC Van, Puijenbroek EP Van, Jong Van den Berg LTW de (2002) Contribution of pharmacists to the reporting of adverse drugreactions. Pharmacoepeidemiol Drug Saf 11(3): 205-210.

12. Fincham JE (1989) Adverse Drug Reaction Reporting and Pharmacists. J Clin Pharm Therapeutics 14: 79-81.

13. Lindquist M, Edwards IR (1993) Adverse drug reactions reporting in Europe: some problems of comparison. Int J Risk Saf Med 4: 35-46.

14. Mohamed SS, Mahmoud AA, Ali AA (2014) The role of sudanese community pharmacists in patients ' self-care. International journal of clinical pharmacy 36(2): 412419.

15. Ibrahim A, Scott J (2013) Community pharmacists in Khartoum State, Sudan: their current roles and perspectives on pharmaceutical care implementation. International journal of clinical pharmacy 35(2): 236243.

16. Bawazir SA (2006) Attitude of community pharmacists in Saudi Arabia towards adverse drug reaction reporting. Saudi Pharm J 14(1): 75-83.

17. Toklu HZ, Uysal MK (2004) The Knowledge and attitude of the Turkish community pharmacist toward pharmacovigilance in the Kadikoy district of Istanbul. Pharm World Sci 30(5): 556-562.

18. Jose J, Jimmy B, Al Ghailani AS, Al Majali MA (2014) A cross sectional pilot study on assessing the knowledge, attitude and behavior of community pharmacists to adverse drug reaction related aspects in the Sultanate of Oman. Saudi Pharmaceutical Journal 22(2): 163-169.

19. Toklu HZ, Uysal MK (2014) The Knowledge and attitude of the Turkish community pharmacist toward pharmacovigilance in the Kadikoy district of Istanbul. Pharm World Sci 26(3): 155-159. 
20. Jose J, Jimmy B, Al Ghailani AS, Al Majali MA (2014) A cross sectional pilot study on assessing the knowledge, attitude and behaviour of community pharmacists to adverse drug reaction related aspects in the Sultanate of Oman. Saudi Pharmaceutical Journal 22(2): 163-169.
21. Elkami R, Hassali M, Ibrahim M (2011) Impact of educational intervention for improving pharmacist knowledge in adverse drug reactions (ADR) reporting experience from Malaysia. Open Drug Safety J 2: 47-53. 